\title{
"ENGAÑO COMÚN DE MUCHOS»: LA AMÉRICA DE CERVANTES
}

En la literatura española del Siglo de Oro el recurso al Nuevo Mundo siempre tuvo un marcado carácter ideológico, bien en sentido de exaltación nacionalista - Lope, Calderón, Tirso, etc.- bien de polémica política acerca de la legitimidad de la conquista - por ejemplo, en Las Casas- como ya es sabido ${ }^{1}$. De todos los usos funcionales del tema americanista en la literatura del Siglo de Oro, sin embargo, el que menos ha sido notado por los estudiosos es el que consistía en presentar el Nuevo Continente como una solución práctica de problemas económicos y sociales concretos. Esta afirmación podría parecer tanto más arriesgada en cuanto que se daba, en la España del mismo período, una tradición de análisis económico -el llamado arbitrismo - que achacaba precisamente a América la ruina del país, pero en la creación literaria la solución que se vislumbraba y se ofrecía al público se limitaba al individuo, era a escala de un personaje, y no de una nación. El convencimiento de que en las Indias se podía contar con infinitas posibilidades $\multimap$ así lo parecía- de promoción social se estaba afirmando en muchas conciencias, a causa de las ideas corrientes en la sociedad de la época sobre las riquezas de Ultramar. Y Cervantes, naturalmente, compartía esas ideas, aunque en su obra literaria el modo de demostrarlo fuera distinto de lo que era el planteamiento más común.

En el Quijote no faltan las alusiones a las riquezas americanas, comparadas por el morisco Ricote a la "grangería y conocida ganan-

- La función del tema americanista en la ideología literaria del Siglo de Oro es el argumento de una investigación que actualmente estoy completando. 
cia» de los pícaros y falsos peregrinos. Una hiperbólica cantidad era la que a los ojos de Don Quijote representaban los azotes que Sancho había de darse para salvar a Dulcinea de su encantamiento, cantidad incluso mayor que "el tesoro de Venecia, las minas del Potosí, ponderación usual de la máxima riqueza y magnitud ${ }^{2}$. Huelga ahora traer más ejemplos sobre la imagen de abundancia del Nuevo Mundo en la literatura del Quinientos y Seiscientos españoles; aquí este aspecto se menciona brevemente sólo porque, para la comprensión cabal de la función del tema americano en la literatura, es necesario no olvidar nunca que la asociación espontánea, en la cultura española del último Renacimiento y del Barroco, entre las Indias y unas desmesuradas riquezas no fue una invención literaria. Era un hecho que respondía a una realidad manifiesta, puesto que el oro y la plata americanos contribuyeron en enorme medida al desarrollo de la economía no sólo -o, en el caso de la Península, no tanto- española, como de la europea. Reflejar en las novelas y en el teatro la importancia de este flujo constante e ingente de dinero era materia obligada y debida, para el escritor, como un elemento más entre los que formaban la realidad del momento, pero en los distintos autores también era distinto el fin de ese recurso, la función que en el mensaje ideológico asumía la mención a y el uso de las riquezas del Nuevo Mundo. Por una parte, esa función era en muchos autores esencialmente moralizadora, orientada como estaba hacia la crítica de los nuevos ricos y a lamentar el trastorno de los antiguos y estables valores sociales del mundo tradicional que en aquellos momentos entraba en un rápido proceso de disgregación. Pero esa actitud no era la única. El escritor no

2 Cervantes, Don Quijote de la Mancha, ed. J. B. Avalle-Arce, Madrid, 1979, II, LIV, p. 462, y LXXI, p. 585. Sobre el enfoque americanista de Cervantes en sus obras, véanse J. AlbISTUR, «Cervantes y América», Cuadernos Hispanoamericanos, Enero 1989. R. DEL ARCO Y GARAY, La sociedad española en las obras de Cervantes, Madrid, 1951. J. B. AVAlle-ARCE, «El Celoso Extremeño, de Cervantes», Homenaje. a Ana Marfa Barrenechea, Madrid, 1984. C. Blanco AguiNAGA, «Cervantes y la picaresca», Nueva revista de Filología Hispánica, 11, 1957. J. CAMPOS, «Presencia de América en la obra de Cervantes», Revista de Indias, VIII, 1947. A. K. FORCIONE, Cervantes and the Humanist vision, Princeton, 1982. J. GARcfa ANTEZANA, «Variantes estructurales del "Zeloso Extremeño" ", Anales Cervantinos, XVIII, 1979-80. L. GARCIA LORENZO, «Experiencia vital y testimonio literario», Anales Cervantinos, XV, 1976. M. GARCiA DE LA TORRE, «Realidad histórica y ficción literaria», Anales Cervantinos, XX, 1982. J. A. MARAVALl, Utopia y contrautopia en el «Quijote», Santiago de Compostela, 1976. M. MolHo, «Aproximación al "Celoso Extremeño" ", Nueva Revista de Filología Hispanica, XXXVIII, 1990. A. SÁNCHEZ, «Los rufianes en el teatro de Cervantes», Homenaje a Alberto Navarro, Kassel, 1990. P. VARAS, "El Rufián Dichoso": una comedia de santos diferente», Anales Cervantinos, XXIX, 1991. S. ZIMIC, «La caridad "jamás imaginada" de Lugo», Boletín de la Biblioteca Menéndez Pelayo, LVI, 1980. 
es directamente - abiertamente- un hombre político. Por mucho que pueda interpretar el sentir de un pueblo entero, de una sociedad, o reflejarlo, o influir en él, es decir, hacer ideología, presenta siempre en sus obras los avatares de un individuo, y en este sentido y en el tema americano el recurso a las riquezas de las Indias podía considerarse también como una salida personal, una solución existencial para los problemas individuales.

América podía ser una solución para las dificultades de los personajes literarios, quienes de esa manera tenían una puerta abierta para huir de sus circunstancias. Y, como dice Levin, "escape is the main attraction [...]. The quality of the experience is determined not simply by whence one is escaping but whither". En este sentido, América era la "Tierra de la gran ocasión" de Fernández de Oviedo, «una tierra de promisión donde el hombre podía vivir en paz "una existencia epicúrea" " 3 .

En un estudio reciente, y brindando una interpretación personal del pensamiento cervantino, Albistur reduce a dos solas veces las menciones a América, con su nombre propio, en la entera obra de Cervantes, una en El Licenciado Vidriera y la otra en el Quijote, en el episodio de la criba de los libros y comedias. Dicho así parece que el dato podría llevar bastante lejos, a causa del aparente desinterés del autor, pero más adelante el mismo crítico dice que entre los siglos XVI y XVII el Nuevo Mundo se conocía como Indias Occidentales, con lo que escamotea su misma conclusión, pues resulta que Cervantes no habría mencionado América porque tenía que decir Indias Occidentales. Evidentemente el problema no consiste en averiguar el nombre que Cervantes daba al Nuevo Continente sino lo que opinaba de él. Bajo un nombre u otro, América entraba en los proyectos concretos del escritor, tanto es así que incluso había intentado pasar a ella ${ }^{4}$, y la presencia del Nuevo Mundo queda bien patente en la obra cervantina puesto que al autor no se le escapaba la importancia extraordinaria que podía tener en la literatura y en la vida. Desde este punto de vista, en el Quijote se mencionan los sucesos vitales de algunos personajes secundarios que pasaban a las Indias o ya habían hecho fortuna en ellas -el escudero vizcaíno, la historia del cautivo, etc. (I, pp. 133, 367, 473), pero solamente de pasada. Es éste un hecho tanto más extraordinario en cuanto que en la vida real fueron varios los escritores, empezando

3 H. LEVIN, The Myth of the Golden Age in the Renaissance, Don Mills, Ontario, 1969, p. 95; J. GONZALEZ, «La significación de las Indias para la Historia de España de Oviedo», América y España en el siglo XVI, Madrid, 1982, p. 84; J. M. GOMEZ TABANERA, «La plática del Villano del Danubio de Fray Antonio de Guevara», Revista Internacional de Sociologia, 1966, p. 300.

4 AlBISTUR, op. cit., p. 65. 
por el mismo Cervantes, que intentaron o desearon pasar a las Indias: dejando aparte los casos de Ercilla, que fue de su iniciativa, y en busca, no de fortuna, sino de gloria militar, o de Pedro Ruiz de Alarcón, nacido en Méjico pero español por producción literaria y cultura, varias entre las mejores plumas del Siglo de Oro trabajaron para redactar una petición de permiso para cruzar el Atlántico; Gutierre de Cetina, Alcalá Yáñez, autor del Donado Hablador, Tirso de Molina, S. Juan de la Cruz, Mateo Alemán..., y en la ficción el Buscón Don Pablos, el Lazarillo de Manzanares, el escudero Marcos de Obregón, Alonso mozo de muchos amos, y tantos personajes cervantinos de los que habrá que hablar más abajo. Y es muy importante notar que el pasaje a las Indias, ne las obras literarias, ocurría principalmente en la novela, y en la novela picaresca: el viajero debía ser un miserable, un desarraigado, para que fuera impelido por la necesidad, y sus motivos debían limitarse a la satisfacción grosera de sus necesidades materiales más inmediatas. La abundancia, facilidad y dulzura de la vida en el Nuevo Mundo eran los acicates que movían la voluntad de los perdidos, que podrían dedicarse a la industria en España, pero preferían no hacerlo. En Cervantes la visión del viaje es muy distinta.

\section{La SOluCión literaria del tema americano en CERVANTES}

Se diría que la posibilidad de mejora social en las Indias estuvo cada vez más presente en Cervantes (sobre todo después de que se le denegara la petición de pasar a América), y más en las novelas o en el teatro que en el Quijote. Un aspecto revelador de este hecho es que cuando Cervantes habla del Nuevo Mundo, no lo hace del descubrimiento y la conquista, sino que presenta la vida americana ya estructurada, como parte integrante de la nacional, tal y como España la incorporó y como estaba inmediatamente abierta a la actividad de los emigrantes ${ }^{5}$. ¿Se advierte la existencia de las Indias como algo más que un motivo de exotismo? se preguntaba Campos. El mismo autor encontraba en cervantes la presencia de la imagen, el uso de la creencia porpular en las riquezas americanas, aunque sólo en una comedia, La entretenida. En 1957 De Pedro en su América en las letras españolas había contestado a la misma pregunta con una construcción de interpretación psicológica: así, las críticas vertidas por Cervantes en el Celoso Extremeño o el Licenciado Vidriera se referirían «a la América de los virreyes y oidores, inme-

5 L. DEL ARCo y GARAY, La sociedad española en las obras de Lope de Vega, Madrid, 1942. La cita siguiente es de CAMPOS, op. cit., p. 373. 
diatamente posterior al descubrimiento y la conquistan y en cambio, una vez que se le denegara la autorización a pasar a las Indias, Cervantes se habría forjado una idea utópica, de sueño, sobre la epopeya americana. Así fue como pudo revalorizar la caballería y dar a luz al quijotismo como reivindicación del mundo ideal ${ }^{6}$. Desde luego no parece acertada la explicación de López Estrada ${ }^{7}$, según la cual, como Cervantes no pudo seguir al conde de Lemos a Nápoles ni pudo pasar a América, «viajó por derrotas de la fantasía en los viajes septentrionales y europeos de estos héroes Persiles y Segismunda [...]". Diciendo esto, se pierde de vista la función de cada elemento en su obra. Los viajes de Persiles son de significación moral, casi iniciática, no un hecho culturalista como podía ser irse a Nápoles con el de Lemos. Esta línea de interpretación presentaría un pensamiento débil de Cervantes, interpretación alimentada también por Albistur: Cervantes era un marinero y por lo tanto estaría abierto a la curiosidad. Por esa razón, su interés para con el Nuevo Mundo habría sido puramente anecdótico. Pero diciendo eso se pierde de vista que Cervantes no buscaba el Nuevo Mundo por amor a lo exótico sino para ganarse la vida. El error consiste en querer poner en el mismo plano la ficción literaria y la necesidad vital, creer que es lo mismo la literatura de evasión que la evasión de la necesidad. En este caso concreto, la visión de la sociedad en Cervantes es realista, y el uso de los materiales americanistas es siempre funcional al mensaje, sobre todo profundamente comprensivo de la condición humana. Incluso se diría que Cervantes hubiera querido construir una teoría literaria de la emigración americana mediante los personajes de sus Novelas Ejemplares, y siempre dándoles connotaciones negativas.

En La Española Inglesa ${ }^{8}$, el padre de la protagonista, un rico mercader gaditano, arruinado tras el saqueo de la ciudad, y desesperado por la pérdida de su hija, decidía pasar a las Indias "común refugio de los pobres generosos» donde el adjetivo "generosos» difumina y matiza la palabra "pobre», pero siempre dejando en claro que lo que hace obligado el viaje es una causa de fuerza mayor. Cuando esa situación de necesidad no se da en el mundo cervantino, el personaje se marcha, pero a hacer la guerra en Flandes. La posible ejemplaridad, para el tema aquí tratado, de este hecho, se verifica mediante la comparación con otra novela, La Señora Cornelia. En ésta los dos protagonistas de la historia, don Antonio de Isunza y don Juan de Gamboa, dos caballeros, son descritos en términos absolutamente positivos, como se esperaba que fuesen, esto es «prin-

6 V. DE PEdro, América en las letras españolas del Siglo de Oro, Buenos Aires, 1954, pp. $79-80$. 
cipales», muy "discretos", grandes amigos, bien nacidos, de ilustre sangre. Y cuando deciden ver el mundo, toman como es natural el camino de Flandes, para ejercitarse en el uso de las armas,

llevados del hervor de la sangre moza y del deseo, como decirse suele, de ver mundo, y por parecerles que el ejercicio de las armas, aunque arma $y$ dice bien a todos, principalmente se asienta y dice mejor en los bien nacidos y de ilustre sangre 9 .

Exactamente igual que Cervantes se había embarcado para la más grande ocasión que vieron los siglos. Estos dos personajes literarios y su autor habían demostrado una inclinación muy distinta de la que caracterizaba a otro interesantísimo personaje de otra creación cervantina, el Carrizales de El Celoso Extremeño, quien, en cambio, sí marchó a América. Pero es que éste era un fracasado, y aquéllos dos jóvenes de fortuna. $\mathrm{O}$ tal vez se podría pensar que, para los ojos de Cervantes, las Indias de principios del siglo XVII sólo brindaban la posibilidad de ocupación dedicada hacia el enriquecimiento fácil, y no el noble ejercicio de las virtudes guerreras. Aparentemente, Cervantes compartía la mentalidad oficial corriente orientada a despreciar al actividad mercantil en pro de las armas y las virtudes de la caballería, pero eso era pura ideología. Cervantes va más allá.

En El Celoso Extremeño, el informe cervantino sobre su personaje es explícito: Carrizales, antes de dar título al texto,

[...] se acogió al remedio que otros muchos perdidos de aquella ciudad [Sevilla] se acogen, que es pasarse a las Indias; refugio y amparo de los desesperados de España, iglesia de los alzados [culpables de bancarrota fraudulenta], salvaconducto de los homicidas, pala y cubierta de los jugadores a quien llaman ciertos [fulleros] los peritos en el arte; añagaza general de mujeres libres, engaño común de muchos y remedio particular de $\operatorname{pocos}^{10}$.

En la misma narración, cuando Loaysa va al Nuevo Mundo, - lo hace «despechado y casi corrido» (p. 220). Cervantes, que había buscado el permiso para ir a América, ¿se reconocería en el retrato que pintaba de esos pasajeros de Indias? Lamentable y dramático pensar que la lucidez del autor, volviéndose hacia sí mismo, no encontrara otra imagen que la de un fracasado, como los que inmisericordemente retrataba en su obra...

7 F. LOPez Estrada, Tomás Moro y España, Madrid, 1980, p. 69.

8 M. DE Cervantes, Novelas Ejemplares, ed. J. B. Avalle-ARCE, Madrid, 1987, II, p. 65.

- Novelas Ejemplares, cit. III, p. 171.

10 Novelas Ejemplares, cit. II, pp. 175-176. 
Pero la riqueza del pensamiento cervantino ofrece las claves para superar el aparente pesimismo de su posición, como se recaba de otras de sus obras. Antes que nada, las dos versiones del Celoso Extremeño se cierran de hecho de dos maneras completamente distintas, y como ha señalado Avalle-Arce, ricas en distintos significados. En la primera versión, Loaysa, causante de la deshonra de Carrizales, se iba a la guerra de Flandes, donde encontraba la muerte a causa del estallido de un arcabuz; pero en la segunda, partía para las Indias. "Los dos distintos finales captan dos completamente distintos conceptos de la novela [...] porque en el manuscrito Porras [1. ${ }^{a}$ versión] la novela queda perfectamente cerrada: [...] no cabe duda: la novela no es como la vida». En cambio, la segunda versión es la de la realidad, no literaria, sino existencial. Avalle-Arce pone de relieve las diferencias literarias entre obra cerrada y obra abierta. Desde el punto de vista del análisis de la mentalidad cervantina ante la vida, las dos elaboraciones en cambio indican otros convencimientos. Siempre hay otra oportunidad, parece querer decir, y cabe la posibilidad de hacer de ella un segundo error - como Carrizales, que volvió de América rico en dinero pero no en juicio- o una nueva esperanza - ¿tal vez fuera a ser ése el destino de Loaysa? Pero las posibilidades opuestas de éxito y fracaso las brinda y están situadas en el Nuevo Mundo. Es posible que ésta sea la ejemplaridad de una novela que deja perplejos a quienes la han leído, pero deja también bien en claro que las Indias eran una instancia de algo más que una promoción social: también podían serlo de una redención ética, para quien supiera aprovechar la ocasión. De esa opinión venía a nacer otra obra cervantina, El Rufián Dichoso ${ }^{11}$, y así Cervantes abría una tercera vía de análisis y presentación de la realidad americana, no coincidente ni con el afán de lucro ni con la búsqueda de gloria militar. En El Celoso Extremeño y en El Rufián Dichoso Cervantes ha pintado, en realidad, a dos belitres cuyos destinos divergen diametralmente a pesar de tener orígenes muy parecidos. El paralelismo entre los personajes de ambas obras es evidente, pues ambos habían tenido una juventud tumultuosa. Carrizales "como otro Pródigo" había gastado "así los años como la hacienda" en sus alocados viajes por España, acabando en Sevilla arruinado. Cristóbal de Lugo, el rufián se presenta por sí mismo en los primeros versos de la comedia, y más adelante el alguacil perfecciona los rasgos de su retrato (vv. 504-518). Los dos habían sufrido una crisis personal, el uno por sus problemas económicos y el otro a causa de cuentas pendientes con la justicia y,

1 M. DE Cervantes, El Rufián Dichoso, en Teatro Completo, ed. Sevilla ARroYo-Rey HAZAS, Barcelona, Planeta, 1987. 
lo más importante, ambos acaban sus vidas tras un cambio radical ocurrido a raíz de un viaje a América. El Celoso Extremeño, tras su viaje a las Indias, se convierte de "hombre que empezó dilapidando dinero y mujeres, hasta colocarse en el caso inverso, en el de una tesaurización excesiva, propiamente maniática, de su dinero y mujer" ${ }^{12}$. A su vez, el Rufián Dichoso, tras su crisis de conciencia, y el viaje a Ultramar, emprende una vida que está exactamente en las antípodas de la que había llevado hasta ese momento. En el Celoso Extremeño la América cervantina es el lugar donde se puede amasar una fortuna, sin la cual la nueva vida de Carrizales en España no tendría posibilidad de realizarse. La ejemplaridad tan poco ejemplar del viejo marido depende efectivamente de todo el dinero que tiene, traído de las Indias, que no usa, que ha empleado para comprar a una mujer y para construir lo que a él le parece un dispositivo inexpugnable de defensa. y son los tratos en América los que le permiten volverse avaro, celoso, y, al final, ser derrotado. ¿Carrizales es poco ejemplar por cómo usa de su nueva posición y por sus monstruosos celos o porque se había marchado como todos los perdidos de su calaña a buscar fortuna a las Indias y había regresado igual de mezquino que cuando se embarcara? Sin embargo, hay que notar que en realidad el indiano, es decir el español enriquecido en el Nuevo Mundo, siempre había actuado, en la literatura y en la vida, de esa misma manera. Carrizales no es más que la deformación extrema de un tipo literario ya de por sí caricaturesco. A causa de los prejuicios corrientes, puestos ante un indiano, lectores y espectadores esperaban encontrar un personaje grotesco y censurable y en este sentido, por lo tanto, Carrizales no es distinto de sus compañeros de fortuna, y también en este sentido, por lo tanto, se nos da a entender que Cervantes no apunta a su personaje individual sino al resultado global de las empresas en el Nuevo Mundo. Y en este sentido, en fin, Cervantes está en deuda con la larga tradición moralizadora española ${ }^{13}$.

El Rufián Dichoso era de la misma calaña que el Carrizales primigenio, pero su posterior desarrollo personal no plantea ninguna ambigüedad: se vuelve santo, solución aplastante. De figura negativa se convierte en otra absolutamente positiva, sin ninguna ambigüe-

12 MolHO, op. cit., p. 749; es un análisis muy agudo de la novela. Sobre la psicología de los personajes cervantinos, M. A. ENCINAR, «La formación de personajes en tres Novelas Ejemplares: El Licenciado Vidriera, El Celoso Extremeño y La Fuerza de la sangre», Cervantes, 15, 1, 1995, y H. PERCAS PONSETI, «El "Misterio escondido" en El Celoso Extremeño», Cervantes, 14, 2, 1994.

13 Sobre el indiano como personaje literario, véanse A. URTIAGA, El indiano en la dramática de Tirso de Molina, Madrid, 1965; y D. RfPODAS ARDANAZ, El indiano en el teatro menor español del Setecientos, BAE, 294, Madrid, 1986. 
dad de las que podían empañar la imagen de Carrizales. Fijándose bien en la estructura de las dos novelas, se percibe directamente la diferencia de asunto.

$Y$ por concluir con todo lo que no hace a nuestro propósito, digo que en la edad que tenía Felipo [Carrizales] cuando pasó a las Indias sería de cuarenta y ocho años, y en veinte que en ellas estuvo, ayudado de su industria y diligencia, alcanzó a tener más de ciento y cincuenta mil pesos ensayados (p. 177).

Es una manera muy corta de narrar una aventura americana, pero de hecho para Cervantes el tiempo que Carrizales pasa en el Nuevo Mundo "no hace a nuestro propósito", y en el Celoso Extremeño el episodio americano se despacha en pocas líneas. En el Rufián Dichoso el segundo y tercer acto están ambientados en el Nuevo Mundo. En la primera novela las Indias tienen la función típica de exaltar la riqueza y la facilidad de adquirirla; en la obra teatral, Cervantes las presenta como el campo de lucha de la conciencia personal para alcanzar un nivel moral superior. De ahí que el autor sobrevuele las actividades de carrizales como si fueran algo elemental, cuyo resultado se conociera de antemano, mientras que el rufián-santo debe encontrarse con una realidad dura o incluso hostil para que su carácter se temple y su vocación se forje.

\author{
Está entre aquestos bárbaros aún niña \\ la fe cristiana, y faltan los obreros \\ que cultiven aquí de Dios la viña (II, vv. 1475-1477).
}

Esas Indias, por tanto, son las no evangelizadas, las de los nativos feroces y opuestas a las del mundo paradisíaco del mito del buen salvaje. El carácter instrumental del tema americano en esta comedia de santos podría parecer, por otra parte, dudoso, puesto que el hecho al que se refiere Cervantes "es historia", como el mismo autor dice en algunos momentos de su texto, es decir que Cervantes no eligió libremente trasladar a Lugo-Cruz de Sevilla al Nuevo Mundo, sino que el rufián y luego santo pasó realmente a las Indias. Pero lo que sí es libertad creativa cervantina es el modo cómo es tratado el tema americano en la comedia. La conversión de Lugo ocurre en Toledo, pero ya antes su amo había decidido llevárselo con él a la Nueva España para alejarlo de la vida desordenada que llevaba. Por primera vez se introduce el tema del cambio de horizonte geográfico para mudar también la conducta moral. Esa contraposición entre lo nuevo y lo viejo -físico y ético- es recalcada mucho por Cervantes en los dos siguientes actos de la comedia, en algunos parlamentos entre Fray Antonio -ex Lagartija- y Cruz ex rufián - con una oposición constante entre el aquí (Méjico) y el 
allí (Sevilla) que es en realidad consideración de la enmienda moral ocurrida entre el entonces (vida rufianesca) y el ahora (vida en santidad), como se puede ver en la escena primera del segundo acto: habla Fray Antonio, ex Lagartija, antiguo compinche del rufián

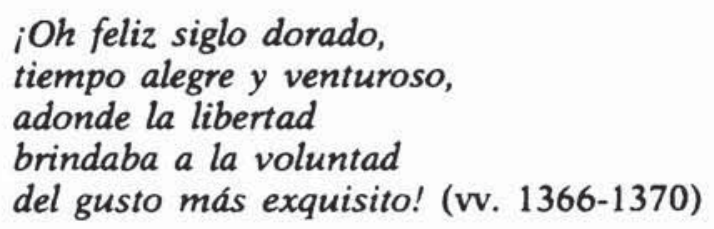

recordando la buena vida pasada en Sevilla. Incluso el diablo, cuando quiere tentar al santo, le recuerda los

\author{
Dulces días, dulces ratos \\ los que en Sevilla se gozan, \\ $y$ dulces comodidades \\ de aquella ciudad famosa [...] (II, vv. 1800-1803).
}

Es muy importante, para entender el significado del Nuevo Mundo en esta obra cervantina, notar que aunque dos de sus tres actos se desarrollan en Méjico, el color local o las referencias a la realidad física americana están del todo ausentes, exceptuando una brevísima alusión a los temporales de las Bermudas y a los indios caníbales, que además es puramente incidental. Cervantes da la idea de que la acción está ocurriendo en el Nuevo Mundo pintando a un nuevo Lugo. Igual que hay una España y una Nueva España ahora hay un rufián y un nuevo Lugo, quien significativamente cambia incluso de nombre y se llama Cristóbal Cruz. Cervantes no pudo llevar a su personaje a otro lugar - hubiera faltado a la verdad histórica- pero no usó el tema americano al estilo de los escritores nacionalistas o del tipismo folclórico, aunque hubiera sido fácil presentar el benéfico influjo de la religión de los españoles en el Nuevo Mundo glorificando así su conquista, como hicieron Lope y Calderón, o introducir datos pintorescos y llamativos. Por el contrario, Cervantes omite la presencia escénica de las Indias y convierte el lugar de la acción en el campo de la posibilidad moral. América en El Rufián Dichoso desempeña el mismo papel funcional que en El Celoso Extremeño; lo que cambia es el uso que los personajes de las dos obras hacen de esa posibilidad, uno mejorando y quedándose, el otro volviendo igual o peor (desde el punto de vista de la sabiduría y la prudencia) que al marcharse, y con el rasgo genial de un tercero - Loaysa - ante quien las Indias se presentan como posibilidad abierta de futuro. Una posibilidad es la de la elevación moral, la otra la del enriquecimiento material, y en Cervantes las dos son inconciliables. . 
No tiene sentido discutir sobre cuál de las dos visiones representar mejor la realidad americana a caballo entre el Quinientos y el Seiscientos; es suficiente notar el valor funcional semejante del mismo elemento compositivo según los diferentes fines que el mismo autor se proponía. Y, desde luego, si este análisis es correcto, habrá que volver a plantearse la opinión que Cervantes podía tener de su situación personal cuando intentara sin éxito convertirse, él también, en un pasajero de Indias.

CEFERINO CARO LÓPEZ 